\title{
Relationship between genetic polymorphisms of methylenetetrahydrofolate reductase and breast cancer chemotherapy response
}

L. Yang*, X.W. Wang*, L.P. Zhu, H.L. Wang, B. Wang, T. Wu, Q. Zhao, D.L.X.T. JinSiHan and X.Y. Wang

Department of Mammary Surgery, Tumor Hospital Affiliated to Xinjiang Medical University, Xinjiang Uygr Autonomous Region, China

*These authors contributed equally to this study. Corresponding author: X.Y. Wang

E-mail: wangxiying_1@163.com

Genet. Mol. Res. 15 (3): gmr.15038679

Received March 31, 2016

Accepted July 11, 2016

Published September 23, 2016

DOI http://dx.doi.org/10.4238/gmr.15038679

Copyright $(2016$ The Authors. This is an open-access article distributed under the terms of the Creative Commons Attribution ShareAlike (CC BY-SA) 4.0 License.

ABSTRACT. Activity of methylenetetrahydrofolate reductase
(MTHFR), an enzyme involved in folate metabolism, is influenced
by mutations in the corresponding gene, contributing to a decrease
in 5,10-MTHF. Due to such polymorphisms, individuals differ in
MTHFR enzyme activity and plasma folate levels. We investigated the
relationship between two common MTHFR polymorphisms (C677T
and A1298C) and breast cancer (BC) chemotherapy response. From
February 2013 to January 2016, 148 advanced BC patients at the Center
Hospital of Cangzhou were enrolled and treated with six different
chemotherapy regimens. Subjects were genotyped using polymerase
chain reaction-restriction fragment length polymorphism. Forty-one
(27.7\%), $70(47.3 \%)$, and $37(25.0 \%)$ patients carried the C/C, C/T, and 
T/T C677T genotypes, respectively; 101 (68.2\%), 42 (28.4\%), and 5 (3.4\%) had the $\mathrm{A} / \mathrm{A}, \mathrm{A} / \mathrm{C}$, and $\mathrm{C} / \mathrm{C}$ genotypes of $\mathrm{A} 1298 \mathrm{C}$, respectively. Total chemotherapy efficacy was $66.9 \%$ (99/148), with 7 (4.7\%), 92 (62.2\%), $36(24.3 \%)$, and $13(8.8 \%)$ cases showing complete response, partial response, no change, and progressive disease, respectively. Chemotherapy regimens did not differ in effectiveness $(\mathrm{P}>0.05)$. Efficacy rates associated with $\mathrm{C} 677 \mathrm{~T} \mathrm{C} / \mathrm{C}, \mathrm{C} / \mathrm{T}$, and $\mathrm{T} / \mathrm{T}$ genotypes were 58.5, 58.6, and $91.9 \%$, respectively, with $\mathrm{T} / \mathrm{T}$ carriers exhibiting significantly better responses than the $\mathrm{C} / \mathrm{C}(\mathrm{P}<0.05)$ and $\mathrm{C} / \mathrm{T}$ groups $(\mathrm{P}$ $<0.05)$. Effectiveness among A1298C A/A, A/C, and C/C carriers was $70.6,64.3$, and $0.0 \%$, respectively, but no difference was established between these genotypes in this regard ( $\mathrm{P}>0.05)$. The MTHFR C677T genotype may be associated with $\mathrm{BC}$ chemotherapy response, and could be of great value in guiding individualized treatment for this disease.

Key words: Genetic polymorphisms; Chemotherapy sensitivity; Methylenetetrahydrofolate reductase; Breast cancer

\section{INTRODUCTION}

DNA methylation can affect gene expression, and is closely associated with tumor incidence and development. Changes in this process, in which the provision of active methyl by folic acid metabolism is crucial, play an important role in carcinogenesis and contribute to the deactivation of tumor suppressor genes (Kim et al., 1997; Jacob et al., 1998). Methylenetetrahydrofolate reductase (MTHFR), an enzyme involved in folate metabolism (Bailey and Gregory, 1999), reduces 5,10-MTHF to 5-methyltetrahydrofolate, the predominant circulating folate form and substrate for the remethylation of homocysteine to methionine, which leads to the subsequent production of $S$-adenosylmethionine, the universal methyl group donor required for DNA methylation (Kim, 2000).

The C677T MTHFR polymorphism is common in breast cancer, and its frequency differs dramatically between countries, areas, and nations. For example, some studies estimate the frequency of the $677 \mathrm{~T}$ allele to be $34 \%$ among Asians, including Han Chinese people, and approximately 22 to $44 \%$ in European populations (Botto and Yang, 2000; Song et al., 2001). In addition, this variant has been shown to influence enzyme activity (Frosst et al., 1995), possibly contributing to folic acid metabolism disorder, and the interaction between this polymorphism and low folate intake has been identified as a potential breast cancer risk factor (Shrubsole et al., 2004). Moreover, a number of reports have suggested that MTHFR variants are associated with methotrexate chemotherapy toxicity and 5-fluorouracil (5-FU) efficiency in patients with breast cancer, gastrointestinal carcinoma, and leukemia (Toffoli et al., 2000, 2003; Ruzzo et al., 2006; Shitara et al., 2010).

The MTHFR gene, comprising 11 exons and 10 introns, is located on chromosome 1p36.3. To date, 20 polymorphic sites have been identified in this sequence, some of which cause a decrease in enzyme activity (Gao et al., 2009; Ma et al., 2009). The C677T and A1298C variants are a particular focus of study, and have been reported to have a close link to several human diseases. It has been found that the enzyme activity of C677T heterozygotes is greater than that of individuals homozygous for the variant allele (Frosst et al., 1995). Furthermore,

Genetics and Molecular Research 15 (3): gmr.15038679 
the 677TT genotype is closely connected with higher plasma homocysteine and lower folate levels (Deloughery et al., 1996). Another common MTHFR polymorphism, A1298T, might also affect the encoded enzyme's specific activity, homocysteine levels, and plasma folate concentration, although to a lesser extent than the C677T variation (van der Put et al., 1998).

Breast cancer chemotherapy has developed remarkably as the drugs used to treat this disease have improved. To date, cyclophosphamide (CTX), anthracycline, 5-FU, and paclitaxel (PTX) combination therapy has been the standard treatment for breast cancer. Chemotherapy has many advantages, not only ameliorating the symptoms of advanced breast cancer, but also prolonging survival time, although individuals can exhibit different responses to the same regimen. Thus, some researchers have focused on variations in drug sensitivity between cases in terms of pharmacogenetics and pharmacogenomics to establish a reliable prediction index and guide individualized treatment. This approach will be of significance to the enhancement of chemotherapy drug efficacy and safety. Therefore, we aimed to analyze the relationship between MTHFR and the sensitivity of breast cancer to chemotherapy.

\section{MATERIAL AND METHODS}

\section{Study subjects}

Between February 2013 and September 2015, 148 patients were recruited from the Cangzhou Central Hospital and all were confirmed as having breast cancer by pathology and cytology. This group comprised Han Chinese women, 29 to 71 years old, with a median age of 50 years. Thirty-nine had previously received chemotherapy, and 58 neoadjuvant chemotherapy. Measurable lesions were observed in the primary foci (62 cases), lymph nodes (57), liver (9), lung (21), and other regions (11). Chemotherapy regimens were as follows: CAF [CTX + epirubicin $(\mathrm{EADM})+5-\mathrm{FU} ; \mathrm{N}=41]$, AT [EADM + PTX; $\mathrm{N}=39$ ], NP [vinorelbine (NVB) + cisplatin (DDP); $\mathrm{N}=19], \mathrm{NA}$ [NVB + EADM; $\mathrm{N}=17$ ], CAP [CTX + EADM + DDP; $\mathrm{N}=$ 16], and TP [PTX + DDP; $\mathrm{N}=16]$. All subjects were confirmed as having measurable lesions by computed tomography. Routine blood examination results and liver and kidney function of the study subjects were within normal range. Moreover, electrocardiogram tests of patients revealed no significant abnormalities, and performance status scores were all over 60 points. All participants signed a consent form.

\section{MTHFR genotyping}

Blood (2 mL) was obtained from all subjects for genomic DNA extraction using a QIAGEN DNA Blood Mini Kit (QIAGEN, Inc., Valencia, CA, USA) following the manufacturer protocol. DNA purity and concentration were determined by spectrophotometric measurement of absorbance at 260 and $280 \mathrm{~nm}$.

MTHFR variants were genotyped using the polymerase chain reaction (PCR)restriction fragment length polymorphism method. Genomic DNA was amplified by PCR using primers specific for the $\mathrm{C} 677 \mathrm{~T}$ and $\mathrm{A} 1298 \mathrm{C}$ regions, and polymorphisms were detected by restriction enzyme digestion (Table 1). The cycling conditions employed for each sequence variant are shown in Table 2. The resulting fragments were analyzed on $2-2.5 \%$ agarose gels.

Genetics and Molecular Research 15 (3): gmr.15038679 
Table 1. Primer sequences and methods used for detection of $M T H F R$ gene polymorphisms.

\begin{tabular}{l|l|l}
\hline C677T & $\begin{array}{l}\text { Forward: 5'-TGAAGGAGAAGGTGTCTGCGGGA-3'; } \\
\text { Reverse: 5'-AGGACGGTGCGGTGAGAGTG-3' }\end{array}$ & Hinfl-based RFLP \\
\hline A1298C & $\begin{array}{l}\text { Forward: 5'-CTTTGGGGAGCTGAAGGACTACTAC-3'; } \\
\text { Reverse: 5'-CACTTTGTGACCATTCCGGTTTG-3' }\end{array}$ & MboII-based RFLP \\
\hline
\end{tabular}

RFLP $=$ restriction fragment length polymorphism.

Table 2. Polymerase chain reaction (PCR) conditions for amplification of the MTHFR gene.

\begin{tabular}{l|l}
\hline Locus & PCR conditions \\
\hline $\mathrm{C} 677 \mathrm{~T}$ & $94^{\circ} \mathrm{C}(2 \mathrm{~min}) ; 40$ cycles: $94^{\circ} \mathrm{C}(30 \mathrm{~s}), 62^{\circ} \mathrm{C}(30 \mathrm{~s}), 72^{\circ} \mathrm{C}(30 \mathrm{~s}) ; 72^{\circ} \mathrm{C}(7 \mathrm{~min})$ \\
\hline A1298C & $94^{\circ} \mathrm{C}(5 \mathrm{~min}) ; 35$ cycles: $95^{\circ} \mathrm{C}(30 \mathrm{~s}), 58^{\circ} \mathrm{C}(30 \mathrm{~s}), 72^{\circ} \mathrm{C}(30 \mathrm{~s}) ; 72^{\circ} \mathrm{C}(7 \mathrm{~min})$ \\
\hline
\end{tabular}

\section{Chemotherapy regimens}

The above mentioned chemotherapy regimens were administered in a 3-week period and curative effect was evaluated after two cycles of treatment.

\section{Evaluation of treatment}

According to the World Health Organization efficacy standards for solid tumors, treatment outcome was categorized as complete response (CR), partial response (PR), no change (NC), or progressive disease (PD). Therapy resulting in CR or PR was considered effective.

\section{Statistical analysis}

Polymorphism frequency data were evaluated for deviation from Hardy-Weinberg equilibrium. Data are reported as medians and ranges or means and standard deviations. All tests were two-tailed, and $\mathrm{P}$ values $<0.05$ were considered statistically significant. Statistical analysis was performed using SPSS version 20.0 (IBM Corp., Armonk, NY, USA).

\section{RESULTS}

\section{MTHFR genotype frequencies and total chemotherapy efficacy}

Among the 148 patients, the distribution of MTHFR C677T genotypes was as follows: C/C, 41 cases (27.7\%); C/T, 70 (47.3\%); and T/T, 37 (25.0\%). For the A1298C variant, the following genotype frequencies were observed: A/A, 101 cases $(68.2 \%) ; \mathrm{A} / \mathrm{C}, 42(28.4 \%)$; and C/C, 5 (3.4\%). Total chemotherapy efficacy was $66.9 \%$ (99/148), with CR being observed in 7 patients (4.7\%), PR in 92 (62.2\%), NC in 36 (24.3\%), and PD in 13 (8.8\%) (Table 3).

\section{Relationship between MTHFR genotype and chemotherapy response}

There were no statistically significant differences between the six chemotherapy regimens in terms of efficacy $(\mathrm{P}=0.41)$. The effectiveness rates associated with MTHFR $\mathrm{C} 677 \mathrm{~T} \mathrm{C} / \mathrm{C}, \mathrm{C} / \mathrm{T}$, and $\mathrm{T} / \mathrm{T}$ genotypes were $58.5,58.6$, and $91.9 \%$, respectively, with $\mathrm{T} / \mathrm{T}$ carriers showing significantly better responses than individuals with $\mathrm{C} / \mathrm{C}(\mathrm{P}<0.05)$ and $\mathrm{C} / \mathrm{T}$ 
genotypes $(\mathrm{P}<0.05)$. The effectiveness of chemotherapy for patients with $\mathrm{A} / \mathrm{A}, \mathrm{A} / \mathrm{C}$, and $\mathrm{C} / \mathrm{C}$ MTHFR A1298C genotypes was $70.6,64.3$, and $0.0 \%$, respectively, although no statistically significant difference was detected between these groups $(\mathrm{P}>0.05$; Table 3$)$.

Table 3. Chemotherapy efficiency rate in patients with different MTHFR genotypes.

\begin{tabular}{l|c|c|c|c|c|c}
\hline & \multicolumn{3}{|c|}{ C677T (\%) } & \multicolumn{3}{c}{ A1298C (\%) } \\
\hline & $\mathrm{C} / \mathrm{C}$ & $\mathrm{C} / \mathrm{T}$ & $\mathrm{T} / \mathrm{T}$ & $\mathrm{A} / \mathrm{A}$ & $\mathrm{A} / \mathrm{C}$ & $\mathrm{C} / \mathrm{C}$ \\
\hline $\mathrm{CR}$ & $2(4.9)$ & $5(7.1)$ & $0(0)$ & $2(2.0)$ & $5(11.9)$ & $0(0)$ \\
\hline PR & $22(53.6)$ & $36(51.4)$ & $34(91.9)$ & $70(69.4)$ & $22(52.4)$ & $0(0)$ \\
\hline $\mathrm{NC}$ & $15(36.6)$ & $19(27.1)$ & $2(5.4)$ & $24(23.8)$ & $10(23.8)$ & $3(60.0)$ \\
\hline PD & $2(4.9)$ & $10(14.4)$ & $1(2.7)$ & $5(5.0)$ & $5(11.9)$ & $2(40.0)$ \\
\hline Total efficiency rate & $24(58.5)$ & $41(58.6)$ & $34(91.9)$ & $72(70.6)$ & $27(64.3)$ & $0(0)$ \\
\hline
\end{tabular}

$\mathrm{CR}=$ complete response $\mathrm{PR}=$ partial response $\mathrm{NC}=$ no change $\mathrm{PD}=$ progressive disease .

\section{Relationship between MTHFR genotype and efficacy of different chemotherapy regimens}

The effectiveness rates of the CAF, AT, NP, NA, CAP, and TP regimens were $58.5(24 / 41)$, 87.2 (34/39), 63.2 (12/19), 52.9 (9/17), 43.8 (7/16), and 81.3\% (13/16), respectively, but no significant difference was established $(\mathrm{P}>0.05)$. As shown in Table 4, the efficacy of all regimens except that of CAP was $100 \%$ in the T/T genotype group; however, owing to the small number of patients for each treatment, no statistically significant difference was observed. Moreover, no patient undergoing AT, NA, CAP, or TP chemotherapy carried the A1298C C/C genotype, and none in the CAP group had the $\mathrm{A} / \mathrm{C}$ genotype. In each chemotherapy regimen subgroup, treatment effectiveness did not significantly differ according to the MTHFR A1298C genotype.

Table 4. Relationship between the MTHFR genotype and chemotherapy efficacy.

\begin{tabular}{|c|c|c|c|c|c|c|c|c|c|}
\hline \multirow[t]{2}{*}{ Regimen } & \multirow[t]{2}{*}{$\mathrm{N}$} & \multicolumn{4}{|c|}{ C677T (\%) } & \multicolumn{4}{|c|}{ A1298C (\%) } \\
\hline & & $\mathrm{C} / \mathrm{C}$ & $\mathrm{C} / \mathrm{T}$ & $\mathrm{T} / \mathrm{T}$ & $P$ & $\mathrm{~A} / \mathrm{A}$ & $\mathrm{A} / \mathrm{C}$ & $\mathrm{C} / \mathrm{C}$ & $\mathrm{P}$ \\
\hline$\overline{\mathrm{CAF}}$ & 41 & $7(63.6)$ & $10(57.1)$ & $7(100.0)$ & 0.37 & $17(70.0)$ & $7(50.0)$ & $0(0)$ & 0.45 \\
\hline$\overline{\mathrm{AT}}$ & 39 & $7(100.0)$ & $12(72.1)$ & $15(100.0)$ & 0.68 & $24(88.9)$ & $10(80.0)$ & - & - \\
\hline$\overline{\mathrm{NP}}$ & 19 & $4(100.0)$ & $5(40.0)$ & $2(100.0)$ & 0.65 & $10(100.0)$ & $2(33.3)$ & $0(0)$ & 0.07 \\
\hline NA & 17 & $2(28.6)$ & $2(50.0)$ & $5(100.0)$ & 0.68 & $7(50.0)$ & $2(100.0)$ & - & - \\
\hline$\overline{\text { CAP }}$ & 16 & $0(0)$ & $5(71.4)$ & $3(42.9)$ & - & $7(50.0)$ & - & - & - \\
\hline$\overline{\mathrm{TP}}$ & 16 & $2(100.0)$ & $7(60.0)$ & $2(100.0)$ & - & $7(60.0)$ & $6(100.0)$ & - & - \\
\hline
\end{tabular}

$\mathrm{CAF}=$ cyclophosphamide $(\mathrm{CTX})+$ epirubicin $(\mathrm{EADM})+$ 5-fluorouracil $(5-\mathrm{FU}) ; \mathrm{AT}=\mathrm{EADM}+$ paclitaxel $(\mathrm{PTX}) ;$ $\mathrm{NP}=$ vinorelbine $(\mathrm{NVB})+$ cisplatin $(\mathrm{DDP}) ; \mathrm{NA}=\mathrm{NVB}+\mathrm{EADM} ; \mathrm{CAP}=\mathrm{CTX}+\mathrm{EADM}+\mathrm{DDP} ; \mathrm{TP}=\mathrm{PTX}+\mathrm{DDP}$.

\section{DISCUSSION}

The MTHFR C677T and A1298C polymorphisms are of clinical significance, and a considerable number of studies have focused on the former. The C677T variant consists of a C-to-T substitution at position 677, causing the replacement of alanine with valine in the translated protein, leading to decreased enzyme stability and activity. With the development of chemotherapy drugs, chemotherapy currently employed has had remarkable achievements in breast cancer treatment. However, the effects of the same chemotherapy may differ between patients. Researchers have therefore proposed that pharmacogenetics and pharmacogenomics might contribute to such drug sensitivity differences between individuals, and could be used to establish a reliable prediction index to guide personalized chemotherapy.

Genetics and Molecular Research 15 (3): gmr.15038679 
Some studies have found that MTFHR polymorphisms correlate with chemotherapy toxicity and the clinical efficacy of 5-FU (Marsh et al., 2000; Lu et al., 2004; Ma et al., 2009). In addition, the C677T variation in this gene has been reported to be associated with the survival of patients with advanced breast cancer, although the A1298C polymorphism was not found to be significantly related to the mortality rate of this disease (Marsh et al., 2000). Martin et al. (2006) concluded that these MTHFR sequence variants do influence patient survival in breast cancer cases, with different genotypes exerting divergent effects on disease outcome, and that this relationship demonstrates race specificity. Shrubsole et al. (2005) reported that the A1298C genotype does not affect risk of death, but the C677T polymorphism may modify breast cancer survival.

In this study, we found that the effectiveness of chemotherapy for patients with the MTHFR C677T T/T genotype was significantly higher than for those carrying the $\mathrm{C} / \mathrm{C}$ or $\mathrm{C} / \mathrm{T}$ genotype. An analysis of various regimens revealed that the A1298C polymorphism of this gene had no significant relationship with breast cancer chemotherapy efficacy, although some differences were noted in this respect. This variant might therefore be a potential marker to predict chemotherapy response of breast cancer patients, albeit with lower sensitivity than the MTHFR C677T polymorphism. van der Put et al. (1998) reported that the effects of the A1298C variation on the cellular level of folic acid are significantly lower than those of the C677T polymorphism, thus the former's impact on chemotherapy efficacy is also weaker than the latter's, consistent with our results.

In conclusion, the MTHFR C677T polymorphism demonstrates greater utility for the development of individualized breast cancer treatment. Future studies using larger sample sizes are needed to confirm this result and improve the applied value of this sequence variation.

\section{Conflicts of interest}

The authors declare no conflict of interest.

\section{REFERENCES}

Bailey LB and Gregory 3rd JF (1999). Polymorphisms of methylenetetrahydrofolate reductase and other enzymes: metabolic significance, risks and impact on folate requirement. J. Nutr. 129: 919-922.

Botto LD and Yang Q (2000). 5,10-Methylenetetrahydrofolate reductase gene variants and congenital anomalies: a HuGE review. Am. J. Epidemiol. 151: 862-877. http://dx.doi.org/10.1093/oxfordjournals.aje.a010290

Deloughery TG, Evans A, Sadeghi A, McWilliams J, et al. (1996). Common mutation in methylenetetrahydrofolate reductase. Correlation with homocysteine metabolism and late-onset vascular disease. Circulation 94: 3074-3078. http://dx.doi.org/10.1161/01.CIR.94.12.3074

Frosst P, Blom HJ, Milos R, Goyette P, et al. (1995). A candidate genetic risk factor for vascular disease: a common mutation in methylenetetrahydrofolate reductase. Nat. Genet. 10: 111-113. http://dx.doi.org/10.1038/ng0595-111

Gao CM, Kazuo T, Tang JH, Cao HX, et al. (2009). MTHFR polymorphisms, dietary folate intake and risks to breast cancer. Zhonghua Yu Fang Yi Xue Za Zhi 43: 576-580.

Jacob RA, Gretz DM, Taylor PC, James SJ, et al. (1998). Moderate folate depletion increases plasma homocysteine and decreases lymphocyte DNA methylation in postmenopausal women. J. Nutr. 128: 1204-1212.

Kim YI (2000). Methylenetetrahydrofolate reductase polymorphisms, folate, and cancer risk: a paradigm of gene-nutrient interactions in carcinogenesis. Nutr. Rev. 58: 205-209. http://dx.doi.org/10.1111/j.1753-4887.2000.tb01863.x

Kim YI, Pogribny IP, Basnakian AG, Miller JW, et al. (1997). Folate deficiency in rats induces DNA strand breaks and hypomethylation within the $\mathrm{p} 53$ tumor suppressor gene. Am. J. Clin. Nutr. 65: 46-52.

Lu JW, Gao CM, Wu JZ, Sun XF, et al. (2004). Relationship of methylenetetrahydrofolate reductase C677T polymorphism and chemosensitivity to 5-fluorouracil in gastric carcinoma. Chin. J. Cancer 23: 958-962.

Genetics and Molecular Research 15 (3): gmr.15038679 
Ma E, Iwasaki M, Kobayashi M, Kasuga Y, et al. (2009). Dietary intake of folate, vitamin B2, vitamin B6, vitamin B12, genetic polymorphism of related enzymes, and risk of breast cancer: a case-control study in Japan. Nutr. Cancer 61: 447-456. http://dx.doi.org/10.1080/01635580802610123

Marsh S, Ameyaw MM, Githang'a J, Indalo A, et al. (2000). Novel thymidylate synthase enhancer region alleles in African populations. Hum. Mutat. 16: 528. http://dx.doi.org/10.1002/1098-1004(200012)16:6<528::AIDHUMU11>3.0.CO;2-W

Martin DN, Boersma BJ, Howe TM, Goodman JE, et al. (2006). Association of MTHFR gene polymorphisms with breast cancer survival. BMC Cancer 6: 257. http://dx.doi.org/10.1186/1471-2407-6-257

Ruzzo A, Graziano F, Kawakami K, Watanabe G, et al. (2006). Pharmacogenetic profiling and clinical outcome of patients with advanced gastric cancer treated with palliative chemotherapy. J. Clin. Oncol. 24: 1883-1891. http://dx.doi. org $10.1200 / \mathrm{JCO} .2005 .04 .8322$

Shitara K, Muro K, Ito S, SawakiA, etal. (2010). Folate intake along with genetic polymorphisms in methylenetetrahydrofolate reductase and thymidylate synthase in patients with advanced gastric cancer. Cancer Epidemiol. Biomarkers Prev. 19: 1311-1319. http://dx.doi.org/10.1158/1055-9965.EPI-09-1257

Shrubsole MJ, Gao YT, Cai Q, Shu XO, et al. (2004). MTHFR polymorphisms, dietary folate intake, and breast cancer risk: results from the Shanghai Breast Cancer Study. Cancer Epidemiol. Biomarkers Prev. 13: 190-196. http://dx.doi. org/10.1158/1055-9965.EPI-03-0273

Shrubsole MJ, Shu XO, Ruan ZX, Cai Q, et al. (2005). MTHFR genotypes and breast cancer survival after surgery and chemotherapy: a report from the Shanghai Breast Cancer Study. Breast Cancer Res. Treat. 91: 73-79. http://dx.doi. org/10.1007/s10549-004-7265-6

Song C, Xing D, Tan W, Wei Q, et al. (2001). Methylenetetrahydrofolate reductase polymorphisms increase risk of esophageal squamous cell carcinoma in a Chinese population. Cancer Res. 61: 3272-3275.

Toffoli G, Veronesi A, Boiocchi M and Crivellari D (2000). MTHFR gene polymorphism and severe toxicity during adjuvant treatment of early breast cancer with cyclophosphamide, methotrexate, and fluorouracil (CMF). Ann. Oncol. 11: 373-374.http://dx.doi.org/10.1023/A:1008337900349

Toffoli G, Russo A, Innocenti F, Corona G, et al. (2003). Effect of methylenetetrahydrofolate reductase $677 \mathrm{C} \rightarrow \mathrm{T}$ polymorphism on toxicity and homocysteine plasma level after chronic methotrexate treatment of ovarian cancer patients. Int. J. Cancer 103: 294-299. http://dx.doi.org/10.1002/ijc.10847

van der Put NM, Gabreëls F, Stevens EM, Smeitink JA, et al. (1998). A second common mutation in the methylenetetrahydrofolate reductase gene: an additional risk factor for neural-tube defects? Am. J. Hum. Genet. 62: 1044-1051.http://dx.doi.org/10.1086/301825

Genetics and Molecular Research 15 (3): gmr.15038679 